\title{
Endoscopic management of coloanal anastomotic disruption: a pilot case
}

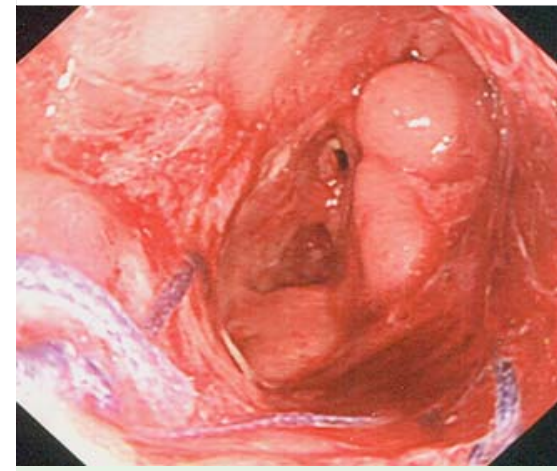

Fig. 1 Disrupted coloanal anastomosis in a 65-year-old man at 2 weeks after surgery for stage IIB moderately differentiated rectal adenocarcinoma.

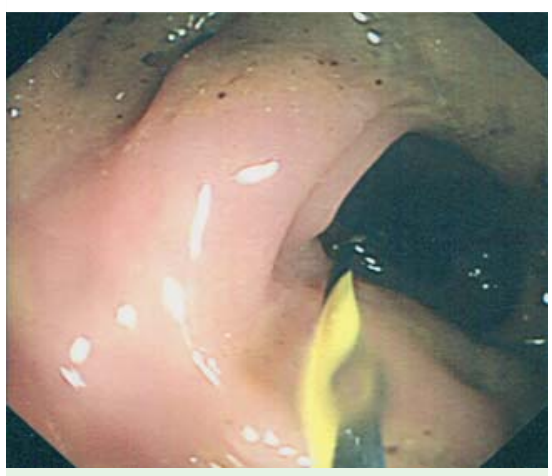

Fig. 2 Guidewire inserted into the colon under endoscopic visualization.

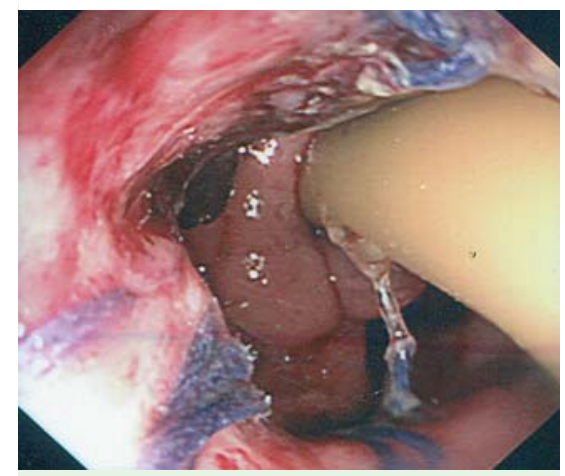

Fig. 3 Foley catheter inserted into the colon over the guidewire.

A 65-year-old man with stage IIB moderately differentiated rectal adenocarcino$\mathrm{ma}, 6 \mathrm{~cm}$ from the anal verge on digital rectal examination, underwent ultra-low anterior resection with coloanal anastomosis and defunctioning loop ileostomy. The anastomosis was $4 \mathrm{~cm}$ from the anal verge.

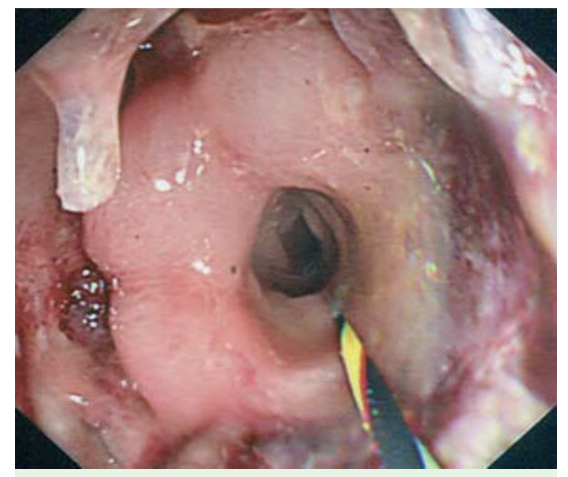

Fig. 4 Colonic end at 3 months after surgery with the guidewire in the lumen.

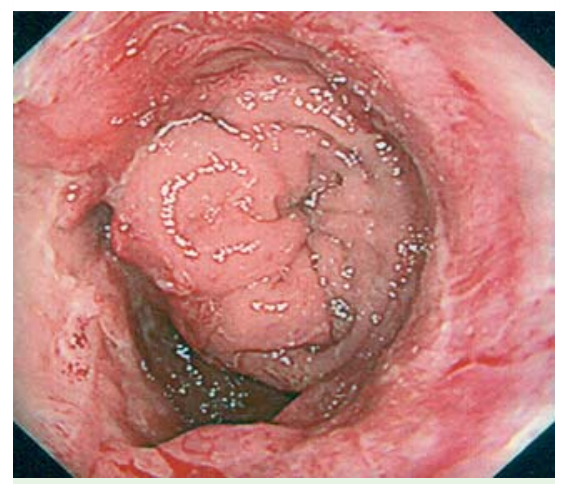

Fig. 5 Colonic end at 5 months after surgery.

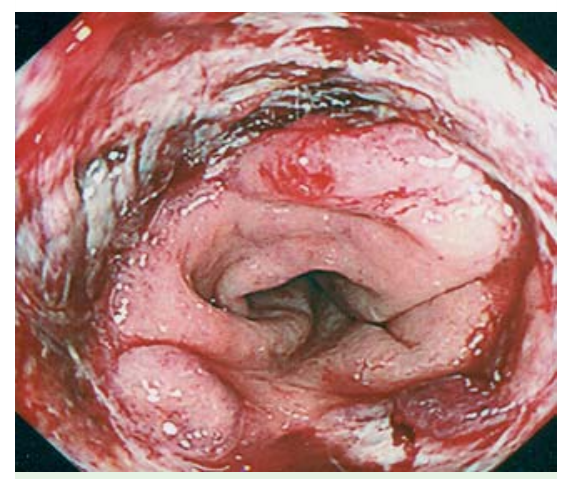

Fig. 6 Healed coloanal anastomosis at 6 months after surgery.

At 1 week after discharge, the patient returned with mild anal pain and seropurulent anal discharge, but no fever. A gentle examination per rectum revealed disruption of the coloanal anastomosis. Computed tomography showed no pelvic or perianal collections. The patient underwent examination with flexible sigmoid- oscopy while under anesthesia. The colonic end of the anastomosis was noted to be lying 1 to $2 \mathrm{~cm}$ away from the proximal end of the anal canal muscles, but the tissue was healthy and not ischemic ( Fig.1). The impression was that of complete coloanal anastomotic disruption with no pelvic collections.

Under endoscopic visualization, a guidewire was inserted into the colon ( $\bullet$ Fig. 2), and a 32-Fr Foley catheter was inserted over the guidewire ( $\bullet$ Fig. 3). The catheter balloon was inflated with $5 \mathrm{~mL}$ of air proximal to the colonic end of the anastomosis. Gentle traction was applied to the Foley catheter, which was taped to the patient's thigh for the first month to keep the colonic lumen open and drain any collections.

Subsequently, for the next 6 months, the catheter was inserted after each monthly anastomotic dilatation but removed within 4 to 5 days. This ensured that the lumen remained patent and that any collections (mainly blood) following the dilatation could be drained. Gradually, the gap between the colonic end of the anastomosis and the proximal end of the anal canal healed with fibrosis, but with no side tracks ( $\bullet$ Figs.4,5). At 6 months, the coloanal anastomosis had fully healed, and an index finger could be easily inserted ( $\nabla$ Fig.6). Barium study confirmed the absence of anastomotic leak or stricture. The ileostomy was reversed without any complications, and the patient had reasonable bowel function.

Current treatment options for coloanal anastomotic disruption include transanal repair of the anastomosis [1], permanent fecal diversion, antibiotics, and/or drainage, depending on the size of the defect or the degree of sepsis [2]. Our method is less invasive and could be suitable in patients without pelvic abscess or sepsis. Further experience is needed.

\section{Endoscopy_UCTN_Code_TTT_1AQ_2AG}

Competing interests: None

\section{Darren Yak Leong Chan, Surendra Kumar Mantoo}

Department of Colorectal Surgery, Khoo Teck Puat Hospital, Singapore 


\section{References}

1 Blumetti J, Chaudhry V, Prasad L et al. Delayed transanal repair of persistent coloanal anastomotic leak in diverted patients after resection for rectal cancer. Colorectal Dis 2012; 14: $1238-1241$

2 Murrell ZA, Stamos MJ. Reoperation for anastomotic failure. Clin Colon Rectal Surg 2006; 19: $213-216$
Bibliography

DOI http://dx.doi.org/

10.1055/s-0034-1393228

Endoscopy 2015; 47: E506-E507

(c) Georg Thieme Verlag KG

Stuttgart · New York

ISSN 0013-726X
Corresponding author

Darren Yak Leong Chan, MBBS (Hons), MRCSEd Khoo Teck Puat Hospital

90 Yishun Central

Singapore 768828

Fax: +65-6602-3700

ylcha22mon@gmail.com 